University of Wollongong

Research Online

Faculty of Law, Humanities and the Arts Papers (Archive)

Faculty of Arts, Social Sciences \& Humanities

$1-1-2018$

Can the Basel and Stockholm Conventions provide a global framework to reduce the impact of marine plastic litter?

Karen Raubenheimer

University of Wollongong, kraubenh@uow.edu.au

Alistair Mcllgorm

University of Wollongong, amcilgor@uow.edu.au

Follow this and additional works at: https://ro.uow.edu.au/lhapapers

Part of the Arts and Humanities Commons, and the Law Commons

Research Online is the open access institutional repository for the University of Wollongong. For further information contact the UOW Library: research-pubs@uow.edu.au 


\title{
Can the Basel and Stockholm Conventions provide a global framework to reduce the impact of marine plastic litter?
}

\author{
Abstract \\ The issues resulting from plastic waste in the marine environment have highlighted a general failure to \\ control this pollutant on both land and at sea. The international community is now realising that the \\ increasing growth in the amount of plastic pollution in the ocean is reaching a critical point. This has led \\ to a questioning of the current international governance arrangements for marine litter. The \\ environmental and socio-economic impacts of marine litter are a symptom of policy failures and greater \\ action is required "upstream" by industry on land to reduce these impacts. The Stockholm and Basel \\ Conventions are international binding instruments that offer the best opportunity to reduce the impacts of \\ plastics and plastic waste globally. We examine weaknesses in how hazardous wastes are categorised \\ and the options to close the gaps in the current framework that allow for and keep pace with innovation. \\ Both conventions are found to be inadequate to manage the entire lifecycle of all plastic applications. \\ Options are suggested for strengthening the international legal and policy framework in order to reduce \\ on a global scale 1) the . quantity of plastic waste generated, and 2) the . hazard of plastics throughout \\ their lifecycle. \\ Disciplines \\ Arts and Humanities | Law

\section{Publication Details} \\ Raubenheimer, K. \& Mcllgorm, A. (2018). Can the Basel and Stockholm Conventions provide a global \\ framework to reduce the impact of marine plastic litter?. Marine Policy, 96 285-290.
}




\title{
Can the Basel and Stockholm Conventions provide a global framework to reduce the impact of marine plastic litter?
}

\begin{abstract}
The issues resulting from plastic waste in the marine environment have highlighted a general failure to control this pollutant on both land and at sea. The international community is now realising that the increasing growth in the amount of plastic pollution in the ocean is reaching a critical point. This has led to a questioning of the current international governance arrangements for marine litter. The environmental and socio-economic impacts of marine litter are a symptom of policy failures and greater action is required "upstream" by industry on land to reduce these impacts. The Stockholm and Basel Conventions are international binding instruments that offer the best opportunity to reduce the impacts of plastics and plastic waste globally. We examine weaknesses in how hazardous wastes are categorised and the options to close the gaps in the current framework that allow for and keep pace with innovation. Both conventions are found to be inadequate to manage the entire lifecycle of all plastic applications. Options are suggested for strengthening the international legal and policy framework in order to reduce on a global scale 1) the quantity of plastic waste generated, and 2) the hazard of plastics throughout their lifecycle.
\end{abstract}

Keywords: marine litter; Basel Convention; Stockholm Convention; SAICM; marine debris; international policy

This research did not receive any specific grant from funding agencies in the public, commercial, or not-for-profit sectors.

\section{Highlights:}

- The lifecycle of plastics classified as non-hazardous is not adequately managed.

- Policy must be designed to support supply and demand and stabilise end-markets.

- Extended Producer Responsibility must incentivise "upstream" design changes.

- Transparency in international trade can provide stability to domestic end-markets.

\section{Introduction}

Plastic is a component of marine litter that has caught the attention of scientists, civil society, policymakers and the public and private sectors. This is due to the ongoing efforts by researchers over decades in raising the profile of the long-term impacts of marine plastic litter. Globally, plastics have been shown for some time to make up 60$80 \%$ of marine litter [1] with percentages higher in some regions [2-4]. More recently, our modern throwaway lifestyles have been blamed for the estimated 4.8-12.7 million metric tons of plastic waste entering our oceans every year [5].

The ecological and socio-economic impacts result from ingestion, entanglement, habitat destruction and chemicals sorbed from or leached into surrounding waters [610]. Microplastics present similar concerns of ingestion, chemical sorbtion and leaching [11]. Research has shown that chemicals added during the manufacturing process of various plastic products, such as flame retardants, stabilisers, Bisphenol A 
(BPA) and Polybrominated diphenyl ethers (PBDE), may leach from ingested plastics and bioaccumulate within organisms [12]. A 2011 report stated that "the United Nations Environment Program has declared plastic marine debris and its ability to transport toxic substances one of the main emerging issues in our global environment" [13].

The costs of cleaning up marine plastic debris are often borne by those who are not responsible for the pollution [14]. This includes the maritime sectors [15]. Plastic waste also raises concerns for human health and long-term food security but actual risks to either are still unknown. The issue of marine plastic litter is global, spanning cultural, geographical, and jurisdictional boundaries. It is spread by winds and ocean currents [10], resulting in a problem of international scale. The transboundary nature of the problem creates a need for attention at the global level. Yet action worldwide has been below expectation with UN Environment reporting in 2006 that marine litter had worsened, citing inadequate legislation as a direct contributor to this failing [16].

At the international level, the agreement with the greatest application to the management of plastics is the Basel Convention on the Control of Transboundary Movements of Hazardous Wastes and their Disposal [17]. This agreement provides solid vision for international governance of plastics. The Preamble states "the most effective way of protecting human health and the environment from the dangers posed by [hazardous and other] wastes is the reduction of their generation to a minimum in terms of quantity and/or hazard potential." Thus, quantity as well as the characteristics of a product are important once it becomes waste.

Much of the discourse at the international level has focused on the application of the Basel Convention to the transboundary movement of waste that is classified as hazardous, particularly from north to south [18-21]. Research has also found that a large portion of the trade in waste is south-south (ref) but that the majority of trade in hazardous waste is north-north $[18,22]$. The increasing trade in eWaste and the distinction under the Basel Convention between waste and non-waste is currently also a focal point for the Secretariat of the Basel Convention [23].

The current policy framework does not classify plastics as hazardous unless they contain persistent organic pollutants (POPs) regulated under the Stockholm Convention on Persistent Organic Pollutants [24] or if they meet certain criteria under the Basel Convention. As per the latter, plastics from household wastes are regarded as "other" wastes "requiring special consideration" (Annex II) and for the most part do not fall within the discussions on hazardous wastes.

This article focuses on plastic as a non-hazardous waste. The limitations and opportunities of the international legal and policy framework to reduce the impact of plastics throughout their lifecycle are discussed. In particular, the roles of the Basel Convention and the Stockholm Convention are examined. Options are suggested for strengthening the international legal and policy framework in order to reduce on a global scale 1) the quantity of plastic waste generated, and 2) the hazard of plastics throughout their lifecycle. 


\section{Increasing concern at the global level}

Concern over the risks posed by marine plastic litter has been raised in a number of international fora over previous decades. In 2005, the UN General Assembly drew specific attention to marine debris, noting the lack of information and data on the issue [25], and again in 2012 in the outcome document entitled 'The future we want' [26]. The latter recognised the negative effect of marine plastic pollution on ocean health and marine biodiversity and governments committed to reducing the incidence and impacts of such pollution by 2025 . The United Nations Open-ended Informal Consultative Process on Oceans and the Law of the Sea focused on marine debris at its $6^{\text {th }}$ and $17^{\text {th }}$ meetings in 2005 and 2016 respectively. Resolutions on the matter were also adopted at the first three United Nations Environment Assembly (UNEA) meetings in 2014, 2016 and 2017. Marine pollution in the form of plastics and microplastics was included in the 14-point call to action at the first UN Oceans Conference in June 2017 [27]. A 2014 UN report calculated the cost in damage to marine ecosystems by plastic waste at US $\$ 13$ billion, adding that this was likely an underestimation [28].

Although the management of plastics is not the primary objective under other fora, they are of concern. In 2016, Parties to the Convention on Biological Diversity [29] adopted a decision on the prevention of marine litter (COP XIII/10) and published a report on the impacts to marine and coastal biodiversity [30]. The release of microplastics was the focus of reports published by GESAMP [10], the FAO [31] and the IUCN [32]. The Conference of the Parties to the Convention on Migratory Species (CMS) adopted resolutions in 2011 and 2014 specific to marine debris and published three reports on the matter [33]. The International Maritime Organization (IMO) is investigating possible releases of micro- and macroplastics into the marine environment through activities permitted under the London Convention and its Protocol [34].

In addition to the efforts listed here, guidelines were developed under the Basel Convention for the environmentally sound management of all forms of plastic waste [35] as well as hazardous eWaste, much of which contains plastic [36]. Although not a conclusive listing, these efforts illustrate the level of concern over the environmental impacts by plastic waste and signals a clear intent to find opportunities for solutions within the current policy framework. However, marine plastic litter is essentially a symptom of a land-based problem. It is not only marine environments that require protection from plastic waste, but also human and ecosystem health. A lifecycle approach is required that not only prevents the generation of plastic waste but also reduces the hazard of plastic products.

\section{Managing the lifecycle of plastics within the current international legal}

\section{framework}

Protection of the marine environment from pollution is the objective of three instruments at the global level, thereby inferring prevention of plastic pollution. The Law of the Sea Convention [37] aims to protect and preserve the marine environment from both sea- and land-based sources of pollution. Terrestrial impacts are not targeted but are implied if pollution of the marine environment results. MARPOL Annex V [38] and the London Convention and its Protocol [39] prohibit the discharge or intentional dumping at sea of plastic waste in all maritime zones globally. With the 
majority of marine plastic litter originating on land [40], the ability of these instruments to globally reduce the hazard and quantity of plastic waste is therefore limited by their geographic scope.

There is increased recognition for the need to address the issues of pollution "upstream" to reduce the generation of hazardous and other wastes. This is often promoted through the circular economy approach [41-43]. Policy can incentivise endmarkets for plastic waste [44], but establishing a circular economy may not necessarily maximise all the social and environmental outcomes possible.

Protection of human health and the broader environment are the objectives of both the Stockholm Convention and the Basel Convention. The former aims to achieve this through the elimination of POPs and the latter through the environmentally sound management of hazardous and other wastes. Together, these instruments provide the greatest opportunity to address the impacts of plastics throughout their lifecycle by regulating the POPs that may be used in the manufacture of plastics as well as the international trade in plastic waste. The Basel Convention has 186 Parties [45] and the Stockholm Convention has 181 Parties [46] (both including the EU), providing a high level of international participation and further supporting the opportunity to manage the hazard and quantity of plastics globally.

\section{Application of the Basel Convention to the lifecycle of plastics}

The Basel Convention establishes a broad duty for countries to reduce to a minimum their generation of plastic waste (Article 4.2), but primarily provides measures to reduce the quantity and hazard of plastics at the waste phase. Plastics are classified as "other waste" unless they display certain defined characteristic that would deem it "hazardous." The cross-border transportation of plastic waste, be it "hazardous" or "other," is to be regulated by Parties. The Convention intends for Parties to manage such waste within the country it is generated or imported in an "environmentally sound" manner (Article 4.2).

\subsection{Management through trade restrictions}

A Party to the Basel Convention may list plastic waste as hazardous within domestic legislation (Article 3.1). Trade of plastic waste with this Party from other Parties is then not permissible (Article 4.1). Further obligations are placed on the exporting Party which must disallow the trade of plastic waste if the management of such waste by the receiving Party is not deemed environmentally sound (Article 4.2.e). Likewise, if the authority of the importing Party believes the waste imported will not be managed appropriately, it must also disallow the trade (Article 4.2.g). Trade of plastic waste is not allowed with countries that are not Party to the Convention unless a prior arrangement is negotiated between them (Articles 4.5, 11).

The Convention allows for the trade of plastic waste between Parties if the exporting Party does not have the technical capacity and infrastructure to ensure environmentally sound and efficient disposal. A Party may also export plastic waste if it is destined for recycling or recovery (Article 4.9). However, trade that is allowed must be reduced to a minimum (Article 4.2.d). If plastic waste is not intended for export, Parties must ensure adequate disposal facilities are available (Article 4.2.b). 


\subsection{Limitations of the Basel Convention}

\subsubsection{The management of plastic wastes}

The Basel Convention defines environmentally sound management of hazardous wastes or other wastes as "taking all practicable steps to ensure" such wastes are managed in a manner "which will protect human health and the environment against the adverse effects which may result from such wastes" (Article 2.8). This has been viewed as too vague [47] but general guidance is elaborated in the Technical guidelines for the identification and environmentally sound management of plastic wastes and for their disposal [35].

As per the Basel Convention, acceptable disposal options for plastic waste include landfill and incineration (Article 2.4, Annex IV). The guidelines for plastic waste promote the waste hierarchy, emphasising material recycling over landfill. Guidelines for both landfill and incineration have also been developed as well as for the management of electronic waste (eWaste), wastes collected from households and wastes that may contain internationally restricted chemicals. ${ }^{1}$ Guidelines are also provided for the appropriate management of plastic wastes contaminated by dangerous substances such as pesticides (Y4) and plastic wastes from healthcare facilities (Y1, Y3).

This suite of guidelines aims to reduce the volume and the harm potential of end-oflife plastics. They are, however, non-binding, making compliance difficult to enforce. In addition, the Basel Convention provides no indicators, targets, timelines or reporting for reductions in generation of plastic waste or the trade thereof, which also makes progress difficult to measure at the national, regional or global level.

\subsubsection{China: an example of implementation shortfalls}

Recent restrictions in China illustrate the challenges of ensuring compliance with the trade regulations and guidelines of the Basel Convention, resulting in ongoing harm to human health and the environment.

\subsubsection{Ensuring environmentally sound management practices}

China has traditionally imported an estimated $56 \%$ of globally traded plastic waste, including $87 \%$ of plastic waste exported from Europe [48]. Despite China and the EU being Party to the Basel and Stockholm Conventions, China's recycling industry has been responsible for unacceptable environmental harm [49]. This led to the implementation by China of the National Sword policy in February 2017. In July 2017, China registered a number of plastic wastes with the WTO, listing such low levels of acceptable contamination that difficulties in complying with these import standards could effectively eliminate importation of foreign plastic waste. Environmental damage was cited as the reason for these strengthened trade controls. China ratified the Basel Convention in 1991, which brings into question the effectiveness of the Convention to address the human and environmental impacts of plastic waste on a global scale. Not only does the Convention require prior consent

\footnotetext{
${ }^{1}$ All guidelines developed under the Basel Convention are available at: http://www.basel.int/Implementation/Publications/LatestTechnicalGuidelines/tabid/5875/Default.aspx
} 
between the exporting and importing states [23], information from the state of import must be provided confirming the licensed disposer is capable of "environmentally sound management of the wastes in question" (Article 6.3.b).

\subsubsection{National capacity is a global issue}

To ensure the impacts of plastic waste are reduced globally, measures must be put in place to ensure the facilities and the technical capacity of countries are adequate to deal with all plastic wastes generated. In support of this, the Basel Convention requires Parties to ensure adequate and environmentally sound disposal facilities are provided (Article 4.2). Only where such facilities or the technical capacity are not available to ensure environmentally sound and efficient disposal may the waste be exported (Article 4.9). Competent government departments responsible for inspection and enforcement may need to be assessed to ensure they have the authority and the resources to ensure compliance with domestic regulations that give effect to the global standards and regulations [18].

China's National Sword policy provides an example of the need for trade transparency to prevent issues resulting from a lack of capacity. A large team of Chinese authorities was required to inspect domestic recycling facilities [50]. The capacity of Chinese ports to comply with increased inspection requirements was also assessed, with many removed from the list of permissible trading ports [51, 52]. The substantial reductions on imports of foreign plastic waste into China has led to capacity issues within exporting states that have not developed adequate facilities, relying instead on trade to manage their domestic plastic waste [51, 53].

\section{Application of the Stockholm Convention to the lifecycle of plastics}

The Stockholm Convention aims to reduce and/or eliminate emissions and discharges of POPs. These are chemicals are known for their toxicity, persistence and bioaccumulation [54]. The Convention promotes the role that manufacturers of POPs can play in 1) reducing the effects of their products at all stages of their lifecycle and 2) providing information to everyone on the hazardous properties of the chemicals they produce (Preamble). Thus, the hazard potential of plastic products is reduced by influencing the design phase through restrictions on the use of certain POPs during manufacture.

A reduction in the quantity of plastics containing POPs can be incentivised by invoking existing measures under the Convention to regulate the import and export of POPs destined for use in plastics (Article 3.2) as well as plastic waste containing or contaminated with POPs (Article 6.d). This supports the objective of the Basel Convention for States to sustainably manage their own hazardous wastes and to do so within their own borders.

Some POPs listed in Annex A of the Convention may be used in the manufacture of plastics [35]. Parties to the Convention must ensure the elimination of Annex A POPs by regulating their production and use, as well as their import and export. International trade of Annex A POPs is only permitted for the purpose of "environmentally sound disposal" or other purposes permitted under the Convention. Export of such chemicals to non-Parties must be strictly controlled with a certificate 
provided annually by the receiving non-Party to the exporting Party (Article 3). The environmentally sound disposal of waste containing chemicals listed in Annexes A and $\mathrm{B}$ does not include recovery, recycling, reclamation, direct reuse or alternative uses of persistent organic pollutants. Such wastes may also not be transported across international borders without taking into account the Basel Convention. Wastes that contain or are contaminated with POPs that are listed under Annexes I and VIII of the Basel Convention are therefore regulated when traded internationally. These measures can be applied to littered plastic waste that sorbs toxins already present in the surrounding environment in order to prevent the re-entry of banned POPs into the market [55].

\subsection{Limitations in reducing the impacts of plastics}

\subsubsection{Implications for recycling facilities}

Listing a chemical component of plastics can have implications for the collection, transport, handling, recycling and recovery of such plastic wastes. A regional example is the requirement for recycling facilities to ensure secondary pellets and flakes exported to Europe meet the EU Directive on the restriction of the use of certain hazardous substances in electrical and electronic equipment [54-57]. This comes at a cost for facilities in specialised equipment and additional administrative procedures to meet monitoring and reporting requirements, potentially limiting the number of facilities that can comply.

\subsubsection{Limitations of the Stockholm Convention}

The Stockholm Convention provides binding measures to reduce the harm potential of plastic products throughout their lifecycle, including the waste phase. Some flame retardants used in plastic production have been listed in Annex A of the Convention, requiring their production and use to be eliminated by Parties [58]. The application of the Convention to plastics is limited to those products containing or contaminated with listed POPs.

An estimated $26 \%$ of global volume of plastics produced is for packaging applications [43]. Packaging is unlikely to contain flame retardants. Packaging intended for contact with food is often strictly regulated and is unlikely to contain chemicals listed under the Stockholm Convention. In the EU, for example, food-contact materials made from virgin plastics are regulated [59] separately from food-contact materials made from recycled plastics [60]. The Stockholm Convention therefore has limited application in reducing the generation of plastic food packaging waste or the potential for such packaging to cause harm in the environment. The same would apply to other plastics that are not manufactured with restricted POPs, further limiting the global effect of the Convention on the reduction of hazard and quantity of both plastic products and plastic waste.

\section{Towards a globally regulated lifecycle of plastics}

Examination of the international legal framework indicates substantial limitations in stimulating a reduction in 1) the global quantity of mismanaged plastic waste as well 
as 2) the hazard potential of plastic products throughout their lifecycle. Establishing a circular economy may not necessarily achieve the greatest possible reduction in harm to humans and environment without also slowing and shrinking this economic model. Gaps in the current policy framework may be closed through the amendment and/or development of binding or voluntary instruments. This is supported by the recent resolution adopted by the UN Environment Assembly (UNEP/EA.3/L.20) which called for global action to, inter alia, develop action plans that encourage "resource efficiency, including prevention and increasing collection and recycling rates of plastic waste and re-design and re-use of products, materials and avoid the unnecessary use of plastic and plastic containing chemicals of particular concern where appropriate." As per the Resolution, policies and measures must also be prioritised at appropriate scale in order to prevent plastic waste entering the marine environment.

\subsection{Options for measures to reduce harm from plastics}

The technical guidelines for plastic wastes adopted in 2002 under the Basel Convention advise that "waste prevention or reduction involves both upstream alterations in product design as well as alterations in consumer habits." However, no suggestions on how to achieve this are provided. As noted by these voluntary guidelines, the focus is on the management of plastics once they become waste, particularly the recycling thereof. The low rate of recycling globally [61] and the projected increase in production of plastics call for the consideration of an improved regulatory approach to reduce the quantity and harm of plastic and the resulting waste. This may be in the form of a protocol or annex to an existing agreement, e.g. the Basel Convention, or a new international legally binding instrument.

\subsubsection{Reducing quantity of mismanaged plastic waste}

Reframing wastes as a resource [20] can further support the waste hierarchy promoted in the guidelines for plastic waste developed under the Basel Convention, particularly by ensuring transparent and stable domestic or international end-markets for secondary products. Recyclers require a secure source of feedstocks, both in quality and quantity, as well as stable demand for their product in order to remain profitable. Policy measures can assist in stabilising end-markets by, for example, generating supply through high land-fill taxes and creating demand through targets for recycled content [62] and responsible procurement policies.

A primary objective of a new plastics instrument would be the reduction in waste generation. An example of legislation that can assist is the Norwegian amended waste regulation (No. 1289/2017), which provides a good example of the role Extended Producer Responsibility (EPR) can play in reducing packaging waste. The regulation makes use of EPR implementations generally in use today. These provide a financial tool in which producers must pay for the collection of their product. As per the regulation, those supplying the Norwegian market with a minimum of $1000 \mathrm{~kg}$ of a packaging type per year must join an approved compliance scheme to finance the collection, soring, recycling and other process of the waste packaging. This alone does not necessarily incentives the desired design improvements. The regulation therefore stipulates that packaging may only be placed on the Norwegian market if it meets the design, reuse and recycling requirements as defined by the regulation. A 
percentage of the materials must be recyclable into marketable products in compliance with community standards. In addition, the percentage decrease in packaging placed on the Norwegian market and the waste generated must be reported on annually, showing a decrease in both each year [63].

As noted by the guidelines established under the Basel Convention for the environmentally sound management of plastic waste, the environmental and health impacts of plastic waste are not addressed. Improvements to the reduction in hazard potential of plastic wastes and products therefore requires addressing.

\subsubsection{Reducing hazard}

The hazard of plastic waste, as well as hazards posed during the use, reuse, repurposing and recycling of plastic products, can be reduced through the Stockholm Convention by eliminating the use of POPs and the recycling of plastic products that may contain them. Chemical additives not listed under the Stockholm Convention for elimination or reduction can be further managed through the Inter-Organization Programme for the Sound Management of Chemicals (IOMC) [64] and the voluntary Strategic Approach to International Chemicals Management (SAICM) framework, particularly through the SAICM focus on endocrine-disrupting chemicals and nanomaterials [65] as well as the Chemicals in Products (CiP) project. Further research is required to determine the ability of SAICM to move the burden of proof to companies to identify and reduce the risks associated with their products. A regional example is the Regulation of the European Parliament and of the Council on the Registration, Evaluation, Authorisation and Restriction of Chemicals (REACH) [66, 67].

\subsubsection{Making the trade of plastic waste more transparent}

Trade controls, such as export taxes and rebates, can help achieve environmental outcomes where domestic enforcement is problematic [68]. They can also provide market stability for secondary raw materials, particularly where illegal trade in waste distorts markets [50,69]. A new binding plastics instrument could have a secondary objective of increasing domestic treatment of plastic waste within the country of generation, in line with the Basel Convention's intention. This could incentivise a reduction in generation of plastic waste and will require further development of international import and export standards and regulations in this regard.

The guidelines developed under the Basel Convention for the transboundary movement of eWaste provide some examples. A distinction is made in these guidelines between hazardous and other wastes, as well as the purpose of the transboundary movement of eWaste and when equipment should be considered as waste or not.

As per the eWaste guidelines, products are not considered waste if their movement is intended for "direct reuse, or extended use by the original owner" or where equipment is destined for "failure analysis, or for repair and refurbishment with the intention of reuse, or extended use by the original owner, for its originally intended purpose." Such distinctions may facilitate the segregated trade of plastics where these products 
are designed for reuse, such as components that can be easily disassembled and reused across models.

The Basel Convention guidelines on plastic refer to pre-user plastic waste and postuser plastic waste. Because pre-user plastic waste generally contains less contamination, these should be categorised and harmonised with the international Harmonized Commodity Description and Coding System developed by the World Customs Organization (HS codes) to facilitate trade of this cleaner waste stream. Similar categorisation may be considered for plastic components destined for reuse.

\subsection{Discussion}

Management of marine plastic debris requires a wide range of legal tools, one of which is enforcement. Because enforcement can be problematic, voluntary instruments have proved popular. Although these instruments are not enforceable, they encourage States to adopt their objectives and standards within domestic legislation. They may also provide an introductory pathway to binding multilateral agreements [70] such as the UNGA Resolution on drift nets that led to a number of agreements and bans on the practice. Voluntary or 'soft' instruments can therefore provide a mechanism to test and normalise concepts prior to inclusion within binding instruments. They can also be more comprehensive and easier to amend [70].

\subsubsection{Facilitating progress}

The Basel Convention guidelines for the environmentally sound management of plastic suggest "upstream alterations in product design" can assist in reducing the quantity and the hazard of plastic waste. The approach is in line with the OECD guidelines on Extended Producer Responsibility (EPR) [71] and supports the development of global industry guidelines that aim specifically to reduce both hazard and quantity of plastic waste.

The plastics associations can play a role in developing sectoral guidelines through consultation with their members as well as other global and regional associations. For example, the Global Plastics Outreach Alliance is seeking to standardise design guidelines and testing protocols for the recyclability of products across the US and EU [72]. Similarly, the Association of Plastics Recyclers has developed a Design Guide for Plastics Recyclability [73] that links packaging design to available recycling infrastructure.

A review mechanism will assist in keeping pace with industry innovation. Collaboration with all relevant sectors, including government, researchers, IGOs and NGOs, during the design and review phases of the guidelines would be critical in achieving the lifecycle approach required to ensure long-term environmental and socio-economic outcomes.

The UN Regional Seas Programme has experience in various measures to reduce marine litter, including monitoring and would be valuable participants in the design and review of industry guidelines. The UN Environment's Global Partnership on Marine Litter would be a suitable forum for the necessary multi-stakeholder cooperation and coordination. Through this platform regional action plans and 
industry guidelines can be harmonised, particularly where regions are challenged by inadequate municipal solid waste services [74].

\section{Conclusion}

The design, manufacture, consumption and final treatment of plastic products may span a number of countries, yet no international legally binding agreement exists to address the potential impacts to the environment and human health throughout the lifecycle of plastic products. Prevention of marine plastic litter requires improved management of "upstream" processes on land. The lifecycle of plastics is now global, yet the current international legal framework does not adequately govern all of these cross-border processes in a coherent manner. The Stockholm Convention and the Basel Convention can play a role in reducing the impacts of plastics globally, including marine litter, and in terms of both hazard potential and quantity of waste mismanaged. Gaps remain in the management of all lifecycle phases for the majority of plastics that are not classified as hazardous. Supporting end-markets through policy that stimulates supply and demand of plastic waste, providing greater transparency for the trade of plastic waste and improving the design of products will assist in reducing the volume of mismanaged plastic waste and the hazard potential of products throughout their lifecycle. This requires cross-sectoral collaboration to develop industry guidelines that are designed to keep pace with and allow for innovation in order to achieve a lifecycle approach and to protect human health and the environment in the long term.

\section{References:}

[1] J.G.B. Derraik, The pollution of the marine environment by plastic debris: a review, Marine Pollution Bulletin 44(9) (2002) 842-852.

[2] M.L. Dahlberg, R.H. Day, Observations of Man-made objects on the surface of the North Pacific Ocean, In: Proceedings of the Workshop on the Fate and Impact of Marine Debris, R. S. Shomura, H. O. Yoshica, (eds). NOAA- TM-NMFS-SWFC-54 (1985) 198-212.

[3] H. Kanehiro, T. Tokai, K. Matuda, The distribution of litter in fishing ground of Tokyo Bay [Japan], Fisheries Engineering 31(3) (1996) 195-199.

[4] UNEP/MAP, Assessment of The State of Pollution of the Mediterranean Sea by Persistent Synthetic Materials, which can Float, Sink or Remain in Suspension, United Nations Environment Programme, Mediterranean Action Plan 1991.

[5] J.R. Jambeck, G. Roland, W. Chris, R.S. Theodore, Plastic waste inputs from land into the ocean, Science (New York, N.Y.) 347(6223) (2015) 768-771. 
[6] E.J. Carpenter, S.J. Anderson, G.R. Harvey, H.P. Miklas, B.B. Peck, Polystyrene spherules in coastal waters, Science 178(4062) (1972) 749-750.

[7] M.A. Browne, A.J. Underwood, M.G. Chapman, R. Williams, R.C. Thompson, J.A. van Franeker, Linking effects of anthropogenic debris to ecological impacts, Proceedings of the Royal Society B 282(1807) (2015) 20142929.

[8] C.M. Rochman, A. Tahir, S.L. Williams, D.V. Baxa, R. Lam, J.T. Miller, F.C. Teh, S. Werorilangi, S.J. Teh, Anthropogenic debris in seafood: Plastic debris and fibers from textiles in fish and bivalves sold for human consumption, Scientific Reports 5 (2015).

[9] A.M. Scheld, D.M. Bilkovic, K.J. Havens, The Dilemma of Derelict Gear, Scientific Reports 6 (2016) 19671.

[10] GESAMP, Sources, fate and effects of microplastics in the marine environment: a global assessment, IMO/FAO/UNESCOIOC/UNIDO/WMO/IAEA/UN/UNEP/UNDP Joint Group of Experts on the Scientific Aspects of Marine Environmental Protection 2015.

[11] M.A. Browne, S.J. Niven, T.S. Galloway, S.J. Rowland, R.C. Thompson, Microplastic Moves Pollutants and Additives to Worms, Reducing Functions Linked to Health and Biodiversity, Current Biology 23(23) (2013) 2388-2392.

[12] R.C. Thompson, S.H. Swan, C.J. Moore, F.S. vom Saal, Our Plastic Age, Philosophical Transactions of The Royal Society B: Biological Sciences 364(1526) (2009) 1973-1976.

[13] C. Stevenson, Plastic Debris in the California Marine Ecosystem: A Summary of Current Research, Solution Strategies and Data Gaps, California Ocean Science Trust, Oakland, CA 2011.

[14] J. Mouat, R. Lopez Lozano, H. Bateson, Economic Impacts of Marine Litter, KIMO International 2010.

[15] A. McIlgorm, H.F. Campbell, M.J. Rule, The economic cost and control of marine debris damage in the Asia-Pacific region, Ocean \& Coastal Management 54(9) (2011) 643-651.

[16] GPA, The State of the Marine Environment: Trends and processes, United Nations Environment Programme (UNEP) Global Programme of Action for the Protection of the Marine Environment from Land-based Activities (GPA), 2006.

[17] 1989 Basel Convention On The Control Of Transboundary Movements Of Hazardous Wastes And Their Disposal, opened for signature 22 March 1989, 1673 UNTS 57 (entered into force 5 May 1992) ('Basel Convention') <http://www.austlii.edu.au/au/other/dfat/treaties/1992/7.html>

[18] J. Krueger, Prior Informed Consent and the Basel Convention: The Hazards of What Isn’t Known, Journal of EnvIronment \& Development 7(2) (1998) 115-137. 
[19] S.A. Khan, E-products, E-waste and the Basel Convention: Regulatory Challenges and Impossibilities of International Environmental Law, Review of European Comparative \& International Environmental Law 25(2) (2016) 248-260.

[20] C.A. Lucier, B.J. Gareau, From Waste to Resources? Interrogating 'Race to the Bottom' in the Global Environmental Governance of the Hazardous Waste Trade, Journal of World-Systems Research, Vol 21, Iss 2, Pp 495-520 (2015) (2) (2015) 495.

[21] C. Lucier, B. Gareau, Obstacles to preserving precaution and equity in global hazardous waste regulation: an analysis of contested knowledge in the Basel Convention, International Environmental Agreements: Politics, Law \& Economics 16(4) (2016) 493-508.

[22] D. Kellenberg, The Economics of the International Trade of Waste, Annual review of resource economics 7(1) (2015) 109-125.

[23] Y. Tseming., F.C. Scott, The Case for U.S. Ratification of the Basel Convention on Hazardous Wastes, New York University Environmental Law Journal 25(1) (2017) 52-107.

[24] 2001 Stockholm Convention on Persistent Organic Pollutants, opened for signature 22 May 2001, 2256 UNTS 119 (entered into force 17 May 2004) ('Stockholm <http://www.austlii.edu.au/au/other/dfat/treaties/2004/23.html $>$

Convention')

[25] UNGA Fifty-fourth Session Agenda Items 40(a) and (c), Results of the Review by the Commission on Sustainable Development of the Sectoral Theme of 'Oceans and Seas', Report of the Secretary-General, A/54/429, 30 September 1999, para. 252. 1999.

[26] UNGA, The Future We Want, 66/288, 66, A/RES/66/288, (The Future We Want) <http://www.un.org/en/ga/search/view_doc.asp?symbol=\%20A/RES/66/288>

[27] United Nations, Our Ocean, Our Future: Call for Action. <https://oceanconference.un.org/callforaction>, 2017 (accessed 20 August 2017).

[28] United Nations Environment Programme (UNEP), UNEP Year Book 2014 Emerging Issues Update: Plastic Debris in the Ocean, 2014.

[29] 1992 Convention on Biological Diversity, opened for signature 5 June 1992, 1760 UNTS 79 (entered into force 29 December 1993) ('Convention on Biological Diversity') <https://www.cbd.int/convention/text/default.shtml >

[30] Secretariat of the Convention on Biological Diversity (CBD), Marine Debris: Understanding, Preventing and Mitigating the Significant Adverse Impacts on Marine and Coastal Biodiversity, Technical Series No.83 2016.

[31] FAO, Microplastics in fisheries and aquaculture, Food and Agriculture Organization of the United Nations 2017.

[32] J. Boucher, D. Friot, Primary Microplastics in the Oceans: a Global Evaluation of Sources, International Union for Conservation of Nature (IUCN) 2017. 
[33] Convention on the Conservation of Migratory Species of Wild Animals (CMS), Contribution from the Convention on the Conservation of Migratory Species of Wild Animals (CMS) to the Report of the Secretary-General on Oceans and Law of the Sea Marine Debris, Plastics, Microplastics, 2016.

[34] International Maritime Organization (IMO), Review of the Current State of Knowledge Regarding Marine Litter in Wastes Dumped at Sea under the London Convention and Protocol - Final Report (LC 38/16), 2016.

[35] Basel Convention Secretariat, Technical guidelines for the identification and environmentally sound management of plastic wastes and for their disposal (UNEP/CHW.6/21), United Nations Environment Programme 2002.

[36] Secretariat of the Basel Convention, Technical guidelines on transboundary movements of electrical and electronic waste and used electrical and electronic equipment, in particular regarding the distinction between waste and non-waste under the Basel Convention (UNEP/CHW.12/5/Add.1/Rev.1), 2015.

[37] 1982 United Nations Convention on the Law of the Sea opened for signature 10 December 1982, [1994] ATS 31 (entered into force 16 November 1994) ('Law of the Sea Convention') $\langle$ http://www.un.org/depts/los/convention_agreements/texts/unclos/unclos_e.pdf $>$

[38] 2011 Regulations for the Prevention of Pollution by Garbage from Ships (Resolution MEPC.201(62)), ATS 13 (entered into force 1 January 2013) ('MARPOL Annex V') <http://www.austlii.edu.au/au/other/dfat/treaties/ATS/2013/13.html>

[39] 1996 Protocol to the Convention on the Prevention of Marine Pollution by Dumping of Wastes and Other Matter, 1972, opened for signature 7 November 1996, [2006] ATS 11 (entered into force 24 March 2006) ('London Dumping Protocol') <http://www.austlii.edu.au/au/other/dfat/treaties/2006/11.html>

[40] A.L. Andrady, Microplastics in the marine environment, Marine Pollution Bulletin 62(8) (2011) 1596-1605.

[41] P. ten Brink, J.-P. Schweitzer, E. Watkins, M. De Smet, H. Leslie, F. Galgani, T20 Task Force Circular Economy: Circular economy measures to keep plastics and their value in the economy, avoid waste and reduce marine litter, 2017.

[42] K.K. Peiry, Basel Convention on the Control of Transboundary Movements of Hazardous Wastes and Their Disposal, The [article], 2013, p. 434.

[43] World Economic Forum, Ellen MacArthur Foundation and McKinsey \& Company, The New Plastics Economy - Rethinking the future of plastics, 2016.

[44] Ellen MacArthur Foundation, The New Plastics Economy: Rethinking the Future of Plastics \& Catalysing Action, 2017.

[45] Secretariat of the Basel Convention, Parties to the Basel Convention on the Control of Transboundary Movements of Hazardous Wastes and their Disposal. <http://www.basel.int/Countries/StatusofRatifications/PartiesSignatories/tabid/4499/ Default.aspx >, 2017 (accessed 12 July 2017). 
[46] Secretariat of the Stockholm Convention, Status of ratification. <http://chm.pops.int/Countries/StatusofRatifications/PartiesandSignatoires/tabid/4500 /Default.aspx >, 2017 (accessed 12 July 2017).

[47] D.J. Abrams, Regulating the international hazardous waste trade: A proposed global solution, Columbia Journal of Transnational Law 28(3) (1990) 827-831.

[48] C.A. Velis, Global recycling markets - plastic waste: A story for one player China. Report prepared by FUELogy and formatted by D-waste on behalf of International Solid Waste Association - Globalisation and Waste Management Task Force, ISWA, Vienna 2014.

[49] Plastics News, China to WTO: Scrap plastic imports banned by year-end. <http://www.plasticsnews.com/article/20170718/NEWS/170719892/china-to-wtoscrap-plastic-imports-banned-by-year-end >, 2017 (accessed 19 July 2017).

[50] Recycling International, Uncertain fate for plastics recycling market. $<$ http://www.recyclinginternational.com/magazine/issue-august-

2017/article/10764/market-analysis-plastics-uncertain-fate-plastics-recyclingmarket>, 2017 (accessed 10 September 2017).

[51] Chinadialogue, China renews clampdown on waste imports. $<$ https://www.chinadialogue.net/article/show/single/en/9954-China-renewsclampdown-on-waste-imports>, 2017 (accessed 10 August 2017).

[52] Resource Recycling, China's Sword effort continues to rattle market. $<$ https://resource-recycling.com/recycling/2017/04/04/chinas-sword-effort-continuesrattle-market/>, 2017 (accessed 10 April 2017).

[53] Engineering and Technology, Chinese 'National Sword' crackdown creates recycling bottlenecks in Europe. $<$ https://eandt.theiet.org/content/articles/2017/09/chinese-national-sword-crackdowncreates-recycling-bottlenecks-in-europe/>, 2017 (accessed 30 September 2017).

[54] Basel Convention Secretariat, General technical guidelines on the environmentally sound management of wastes of wastes consisting of, containing or contaminated with persistent organic pollutants (UNEP/CHW.12/5/Add.2/Rev.1), 2015.

[55] J. DiGangi, J. Strakova, L. Bell, POPs Recycling Contaminates Children's Toys with Toxic Flame Retardants, IPEN 2017.

[56] Directive 2011/65/EU of the European Parliament and of the Council of 8 June 2011 on the restriction of the use of certain hazardous substances in electrical and electronic equipment Text with EEA relevance, OJ L 174, 1.7.2011, p. 88-110 ('RoHS Directive') <http://eur-lex.europa.eu/legalcontent/EN/TXT/?qid=1501548650977\&uri=CELEX:32011L0065>

[57] 2017 Directive (EU) 2017/2102 of the European Parliament and of the Council of 15 November 2017 amending Directive 2011/65/EU on the restriction of the use of certain hazardous substances in electrical and electronic equipment, OJ L 305, 21.11.2017, p. 8-11 (entered into force 15 November 2017)http://eur- 
lex.europa.eu/legalcontent/EN/TXT/?qid=1512061986553\&uri=CELEX:32017L2102>

[58] Secretariat of the Stockholm Convention, All POPs listed in the Stockholm Convention.

<http://chm.pops.int/TheConvention/ThePOPs/ListingofPOPs/tabid/2509/Default.asp $\underline{x}>, 2017$ (accessed 15 July 2017).

[59] 2011 Commission Regulation (EU) No 10/2011 of 14 January 2011 on plastic materials and articles intended to come into contact with food Text with EEA relevance, OJ L 12, 15.1.2011, p. 1-89 ('Regulation on Food Contact Material') <http://eur-lex.europa.eu/eli/reg/2011/10/oj>

[60] 2008 Commission Regulation (EC) No 282/2008 of 27 March 2008 on recycled plastic materials and articles intended to come into contact with foods and amending Regulation (EC) No 2023/2006 (Text with EEA relevance), OJ L 86, 28.3.2008, p. 918http://eur-lex.europa.eu/legal-content/EN/ALL/?uri=CELEX:32008R0282>

[61] R. Geyer, J.R. Jambeck, K.L. Law, Production, use, and fate of all plastics ever made, Science Advances 3(7) (2017).

[62] K. Raubenheimer, A. McIlgorm, Is the Montreal Protocol a model that can help solve the global marine plastic debris problem?, Marine Policy (2017).

[63] 2017 Forskrift om endring i avfallsforskriften (produsentansvar for emballasje), ('Norwegian packaging

<https://lovdata.no/dokument/LTI/forskrift/2017-08-23-1289> amendment')

[64] WHO, The Inter-Organization Programme for the Sound Management of Chemicals (IOMC). <http://www.who.int/iomc/en/>, 2010 (accessed 23 July 2017).

[65] SAICM, SAICM Emerging Policy Issues and Other Issues of Concern. <http://www.saicm.org/Implementation/EmergingPolicyIssues/tabid/5524/language/e n-US/Default.aspx>, 2017 (accessed 23 July 2017).

[66] 2006 Regulation (EC) No 1907/2006 of the European Parliament and of the Council of 18 December 2006 concerning the Registration, Evaluation, Authorisation and Restriction of Chemicals (REACH), establishing a European Chemicals Agency, amending Directive 1999/45/EC and repealing Council Regulation (EEC) No 793/93 and Commission Regulation (EC) No 1488/94 as well as Council Directive 76/769/EEC and Commission Directives 91/155/EEC, 93/67/EEC, 93/105/EC and 2000/21/EC, OJ L 396, 30.12.2006, p. 1-849http://eur-lex.europa.eu/legalcontent/en/TXT/?uri=CELEX:32006R1907>

[67] J. Schenten, M. Führ, SVHC in imported articles: REACH authorisation requirement justified under WTO rules, Environmental Sciences Europe 28(1) (2016) $1-9$.

[68] S. Eisenbarth, Is Chinese trade policy motivated by environmental concerns?, Journal of Environmental Economics and Management 82(C) (2017) 74-103. 
[69] International Solid Waste Association (ISWA), Prevent Marine Plastic Litter Now!, 2017.

[70] P.J. Kershaw, L. Alcaro, E. Garnacho, T. Doyle, T. Maes, S. Painting, Review of existing policies that may be applied to mitigate the impact of marine litter. Deliverable report D1.3. MARLISCO project. MARine Litter in Europe Seas: Social AwarenesS and CO-Responsibility. (EC FP7 Coordinated and support action, SISMML-289042), July 2013, (2013) 50.

[71] OECD, Extended Producer Responsibility: Updated Guidance for Efficient Waste Management, OECD Publishing, Paris, 2016.

[72] Plastics News, Recycling groups create global coalition to harmonize testing. <http://www.plasticsnews.com/article/20171009/NEWS/171009905?template=printth is>, 2017 (accessed 15 October 2017).

[73] Association of Postconsumer Plastic Recyclers (APR), The APR Design Guide for Plastics Recyclability. <http://www.plasticsrecycling.org/apr-design-guide/aprdesign-guide-home>, 2015 (accessed 17 January 2016).

[74] K. Raubenheimer, N. Oral, A. McIlgorm, Combating marine plastic litter and microplastics: An assessment of the effectiveness of relevant international, regional and subregional governance strategies and approaches. A report to UN Environment, 2017. 